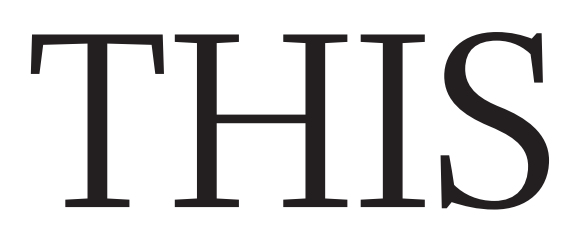

EDITORIALS
QUESTIONS Is this brilliant editorial the best ever written? p.158

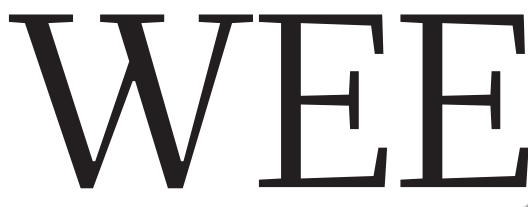

WORLD VIEW Policy has its own problems to reproduce $\mathbf{p} \mathbf{1 5 9}$
IMMUNE Lamprey fish have familiar defence to flu p.160

\title{
Keep a welcome
}

\section{The plight of a record number of refugees is something the West cannot ignore. Humanitarian values should be upheld, and people fleeing war and persecution must be offered protection.}

$\mathrm{I}$ $n$ the refugee crisis facing Europe and the Middle East, an image can be worth a thousand articles or opinion pieces. Academics and humanitarian organizations have long battled to debunk the vicious myths and disinformation that often surround the refugee issue, and to counter often fact-free government policies - to little effect. It took a single iconic and heartbreaking image of a three-yearold Syrian boy, Aylan Kurdi, washed up drowned on a beach in Turkey for the world's conscience to wake up to the plight of refugees.

Science and other academic interests have a long tradition of offering both refuge and professional hope to displaced people. Almost every discipline has its own story of influential figures in the field who arrived with oppression and conflict snapping at their heels. This journal has long chronicled and supported such efforts. In June 1939, for example, Nature published a three-page editorial that concluded that if Britain relaxed its "exceedingly cautious" attitude to accepting refugees, then this would not only defend humanitarian values and academic freedom, but also "might prove in the long run to be wise and sound from the economic point of view".

What is there to say in 2015? Worldwide, there are some 60 million refugees, up from 37.5 million a decade ago - the biggest refugee crisis since the Second World War. Yet the humanitarian response so far has been largely inadequate. The shrill rhetoric in many European Union and other wealthy nations claiming an 'invasion' of refugees doesn't stand up to scrutiny. Four million refugees have fled Syria since the conflict began there in 2011, but last year, the United Kingdom accepted 4,500 Syrian refugees, or just $0.007 \%$ of the UK population. Among the more generous EU countries, Germany took in 40,000 and Sweden 34,000 - the United States took only 4,750. By contrast, over the same period, Turkey temporarily accepted 1.5 million, and Lebanon, a tiny country of just 4.5 million people, took in some 1.15 million refugees, or $26 \%$ of its population.

EU refugee law is a mess. For refugees to apply for asylum, they must first reach a territory outside their own country. But the EU, and other countries, have increasingly sought to circumvent international refugee law by introducing rules to keep refugees out and so prevent them from applying in the first place.

A pernicious $2001 \mathrm{EU}$ directive, for example, erects a barrier by imposing fines and the costs of repatriating illegal immigrants on airline, train, shipping and other carriers, essentially shifting the responsibility for deciding who is a legitimate refugee and who is an illegal migrant from governments to the carrier companies. Predictably, carriers have refused to accept passengers who lack visas. This fortress-Europe mentality explains why, this year alone, more than 300,000 people have embarked on perilous crossings of the Mediterranean - with 2,600 perishing - instead of taking a commercial ferry or airliner to apply for asylum.

There is also no EU-wide asylum status, with decisions on applications left to each member state, and no mutual recognition of positive outcomes by countries. And the seriously flawed 'Dublin Regulation' also obliges the EU member state in which a refugee first arrives to take the refugee's asylum application. This has resulted in frontier countries such as Greece and Italy bearing a hugely disproportionate burden.

The rule also frustrates applicants who have a legitimate preference for a specific country, for example to join their extended family. This encourages irregular movement within the EU, and allows other mem-
"The EU, and other countries, have increasingly sought to

circumvent

international refugee law." with an enforced distribution of refugees throughout EU member states. Merkel last week courageously stated that Germany itself can and will cope with its inflow of refugees, an expected 800,000 this year. The proposal is vigorously opposed by some member states, in particular the Czech Republic, Poland, Hungary and Slovakia.

The public outcry following the photograph of Aylan has given the proposal new momentum, with François Hollande, the French president, last week lending his support, and also the United Nations. The EU will formally discuss the proposal on 14 September - it should be embraced as long-overdue reform.

The scientific community must also play its part. It is in everyone's interest for refugee students and academics to be given opportunities to continue their careers, because otherwise, the Middle East and elsewhere risks losing a generation of talent. The Western academic community must boost efforts to welcome refugee academics and students.

\section{Money matters}

\section{It is not how much people have, it is how much we know they have that stokes inequality.}

$\mathrm{I}$ $\mathrm{t}$ would be so convenient if fundamental laws of nature told us how best to run a society. Governance would be a simple optimization problem, like finding the shortest route through a network; we could do without left-right political confrontation, and just solve the equations. Unfortunately, governance is not a well-posed problem. There must inevitably be balance and compromise: for example, of the rights of the individual against the overall good for society. This is what 